\title{
Impact of vulvovaginal health on postmenopausal women: a review of surveys on symptoms of vulvovaginal atrophy
}

This article was published in the following Dove Press journal:

International Journal of Women's Health

26 July 2013

Number of times this article has been viewed

\section{Sharon J Parish' \\ Rossella E Nappi ${ }^{2}$ \\ Michael L Krychman ${ }^{3}$ \\ Susan Kellogg-Spadt ${ }^{4}$ \\ James A Simon ${ }^{5}$ \\ Jeffrey A Goldstein ${ }^{6}$ \\ Sheryl A Kingsberg ${ }^{7}$}

'Albert Einstein College of Medicine, Bronx, NY, USA; ${ }^{2}$ Department of

Obstetrics and Gynecology, IRCCS

Policlinico San Matteo University,

University of Pavia, Pavia, Italy;

${ }^{3}$ Southern California Center for

Sexual Health and Survivorship

Medicine and Clinical Faculty

University of California Irvine,

Newport Beach and Irvine, CA, USA;

${ }^{4}$ Pelvic and Sexual Health Institute,

Philadelphia, PA, USA; ${ }^{5}$ Obstetrics

and Gynecology, George Washington

University, Washington, DC, USA;

${ }^{6}$ Novo Nordisk Inc, Princeton, NJ,

USA; 'Departments of Reproductive

Biology and Psychiatry, Case Western

Reserve University School of

Medicine, Cleveland, $\mathrm{OH}$, USA
Correspondence: Sharon J Parish

Albert Einstein College of Medicine,

Department of Medicine, Centennial 3,

Montefiore Medical Center,

I I I East 210th Street, Bronx,

NY 10467-2490, USA

$\mathrm{Tel}+\mathrm{I} 7189204783$

Fax +17185156103

Email sparish@montefiore.org
Abstract: Several recent, large-scale studies have provided valuable insights into patient perspectives on postmenopausal vulvovaginal health. Symptoms of vulvovaginal atrophy, which include dryness, irritation, itching, dysuria, and dyspareunia, can adversely affect interpersonal relationships, quality of life, and sexual function. While approximately half of postmenopausal women report these symptoms, far fewer seek treatment, often because they are uninformed about hypoestrogenic postmenopausal vulvovaginal changes and the availability of safe, effective, and well-tolerated treatments, particularly local vaginal estrogen therapy. Because women hesitate to seek help for symptoms, a proactive approach to conversations about vulvovaginal discomfort would improve diagnosis and treatment.

Keywords: health care professional, hypoactive sexual desire disorder, local vaginal estrogen therapy, quality of life, urinary tract infection, vulvovaginal atrophy

\section{Introduction}

The current life expectancy for American women is greater than 80 years and continues to increase. ${ }^{1}$ At the time of the most recent census (2010), 53 million women aged 50 years and older were living in the United States. ${ }^{2}$ Based on the average age of menopause in this population (50.5 years), ${ }^{3}$ and based on increasing life expectancy, most of these women may expect to live almost $40 \%$ of their lives after menopause. Therefore, while some may view menopause as an end-of-life event, it is in fact a midlife event.

Menopause is commonly associated with somatic symptoms, including hot flashes, night sweats, and fatigue, but women are less frequently aware of menopause-related vulvovaginal symptoms, including vulvovaginal dryness, recurrent urinary tract infections (UTIs), and dyspareunia. ${ }^{4-8}$ These symptoms are often associated with vulvovaginal atrophy (VVA), a condition that results from decreased estrogen in the vulvovaginal tissues. ${ }^{9}$ VVA can be diagnosed based on patient-reported symptoms and a physical examination. ${ }^{10,11}$

Symptomatic VVA, which can include an inflammatory reaction to atrophic changes known as atrophic vaginitis, can range in severity from bothersome to debilitating. First-line therapies recommended by the North American Menopause Society include vaginal moisturizers, continued sexual activity, and lubricants. ${ }^{12}$ Lubricants are temporary in their action and are used immediately before and during sexual activity to decrease tissue irritation due to friction. In contrast, vaginal moisturizers are applied internally at regular intervals, are longer-acting, and can decrease vaginal dryness and lower vaginal $\mathrm{pH} .{ }^{13,14}$ These agents do not restore normal vaginal anatomy and in 
some patients may be insufficient or inadequate to resolve symptoms, because they do not treat their underlying cause: the hypoestrogenic vaginal environment. When symptoms persist after first-line therapies are employed, the two primary goals of management are to alleviate symptoms and to reverse atrophic anatomical changes. Vaginal local estrogen therapy (LET) is considered effective and well tolerated for the treatment of moderate to severe symptomatic VVA; ${ }^{12}$ because of minimal systemic absorption of LET, local application is presently recommended over systemic estrogen therapy when VVA is the sole indication. ${ }^{12}$ The cellular and physiological changes that characterize VVA and the results of clinical trials investigating various treatments have been reviewed elsewhere. . $^{12,15}$

The aim of this review is to summarize findings from several recent survey-based studies that have provided profound insight into women's experiences, opinions, and preferences regarding postmenopausal vulvovaginal health. Increased awareness of these patient perspectives among health care providers (HCPs) may help improve the diagnosis and treatment of VVA.

\section{Methods}

To locate recent and relevant surveys, a PubMed search was performed using the search term "postmenopausal women vaginal survey" and was restricted to English-language articles in the date range January 1, 2007, to April 1, 2012. Using the specified search criteria, 107 articles were located. After eliminating trials, studies that did not use surveys, studies that surveyed less than 1000 women, as well as studies that assessed data collected before 2002, a total of seven studies of women in North America and Europe remained (Table 1). ${ }^{5-8,16-18}$ Because the symptoms of VVA are most prevalent in women who have reached menopause, this review focuses on the postmenopausal population. However, relevant data from perimenopausal women have been presented alongside data from postmenopausal women for comparison when both populations were addressed in a single survey. Though this review will emphasize insights learned from these seven key surveys, other recent surveys and key studies on vaginal atrophy that were either cited within the seven key survey publications and/or that were well known and widely accepted by experts in the field were also considered to complement, elaborate on, and amplify these important findings.

For the purposes of this review, VVA is a clinical diagnosis that is made based on an overall impression of symptoms and visual inspection of the vulvovaginal anatomy, with or without testing for confirmatory objective parameters such as $\mathrm{pH}$ or histology. Because all of the key studies considered in this review focused on self-reported experiences and perceptions, it cannot necessarily be concluded that all of the women reporting symptoms of VVA would actually receive that diagnosis from a clinician.

\section{Prevalence of vulvovaginal symptoms} In the seven key studies, , 5,7,16-18 vulvovaginal symptoms were described slightly differently, but the prevalence of symptoms was consistently about 50\% (Table 1). VVA does not result in symptomatology such as discomfort or pain in all women. Gass et $\mathrm{al}^{11}$ found that more than two-thirds (69\%) of women participating in the hormone therapy trials of the Women's Health Initiative had physical evidence of VVA upon clinical examination at enrollment; only $10 \%$ of the same population, however, reported moderate to severe vaginal or genital dryness. This study was unique in that it reported the prevalence of symptoms (ie, vaginal or genital dryness and irritation) and the investigator's clinical impression of atrophy. While many women exhibited signs of VVA (eg, loss of adipose tissue in external genitalia; thinning of pubic hair; atrophic, smooth, pale, or friable vagina; or friable cervix flush with the vaginal vault), not all were symptomatic. ${ }^{11}$

\section{Vulvovaginal discomfort and its effects on women Perceived severity of vulvovaginal symptoms}

The discomfort associated with VVA can have a significant impact on health and overall quality of life (QoL). The VIVA (Vaginal Health: Insights, Views, and Attitudes) study, ${ }^{8}$ which covered the broadest range of countries among the seven key surveys, reported the prevalence of individual symptoms among 1578 women with vaginal discomfort as follows: vaginal dryness, $83 \%$; pain during intercourse, $42 \%$; involuntary urination, $30 \%$; soreness, $27 \%$; itching, $26 \%$; burning, 14\%; and pain when touching the vagina, $11 \%$. In the same study, most women with discomfort (62\%) reported the severity of these symptoms as moderate or severe. Santoro and $\mathrm{Komi}^{5}$ found vaginal dryness and sexual pain to be moderately or very bothersome in $42 \%$ of postmenopausal women who were not currently taking estrogen. Another study corroborated these findings, with $38 \%$ of postmenopausal women reporting that their long-term vaginal dryness was a significant problem; these women rated the problem 5 , 6 , or 7 on a Likert scale, with responses ranging from 1 (not a problem) to 7 (a very significant problem). ${ }^{19}$ 

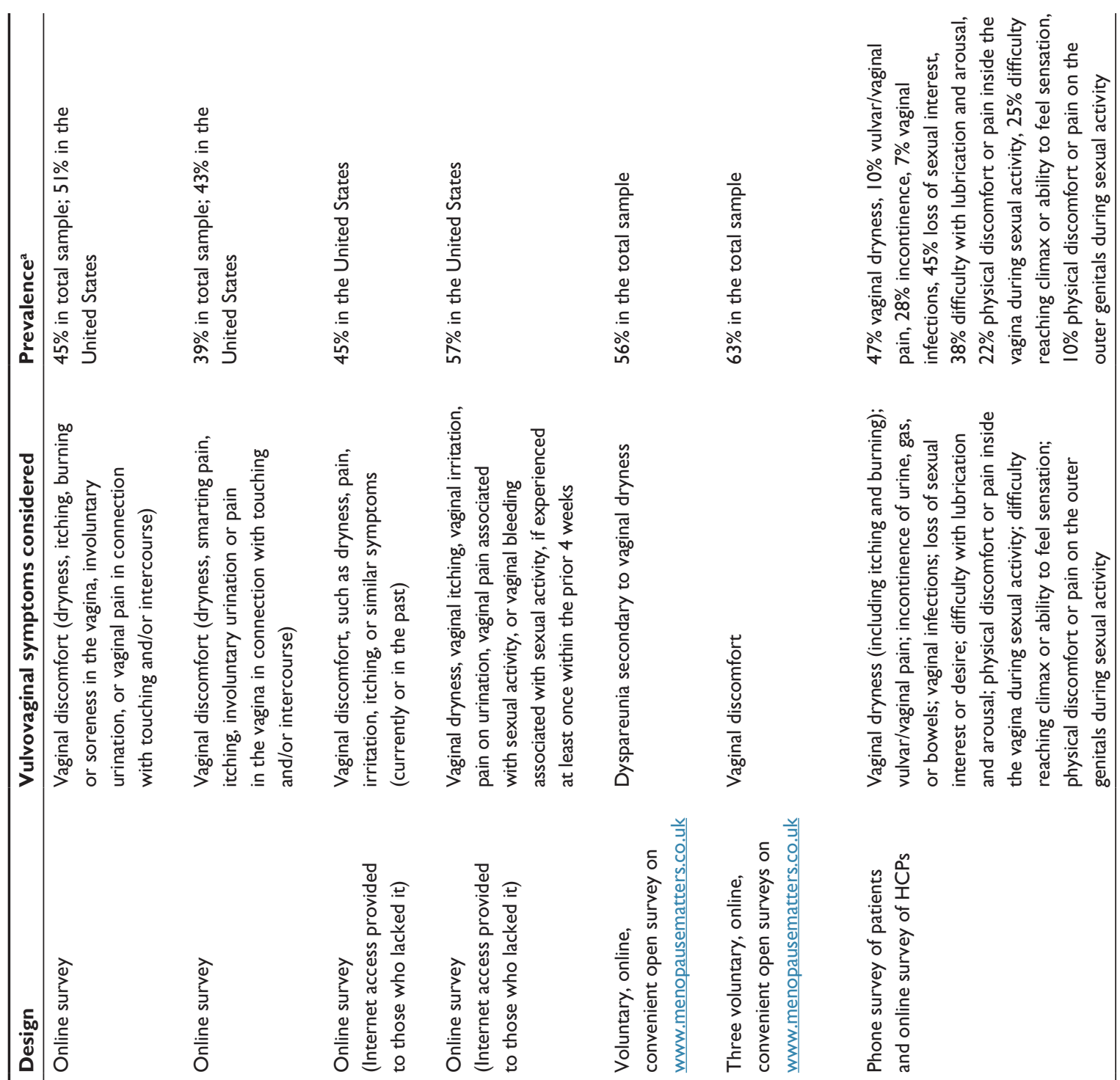

宮客 言

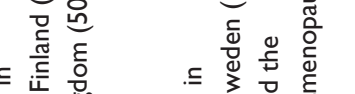

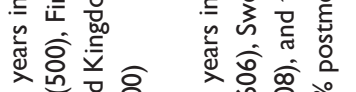

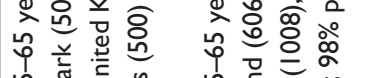

นी
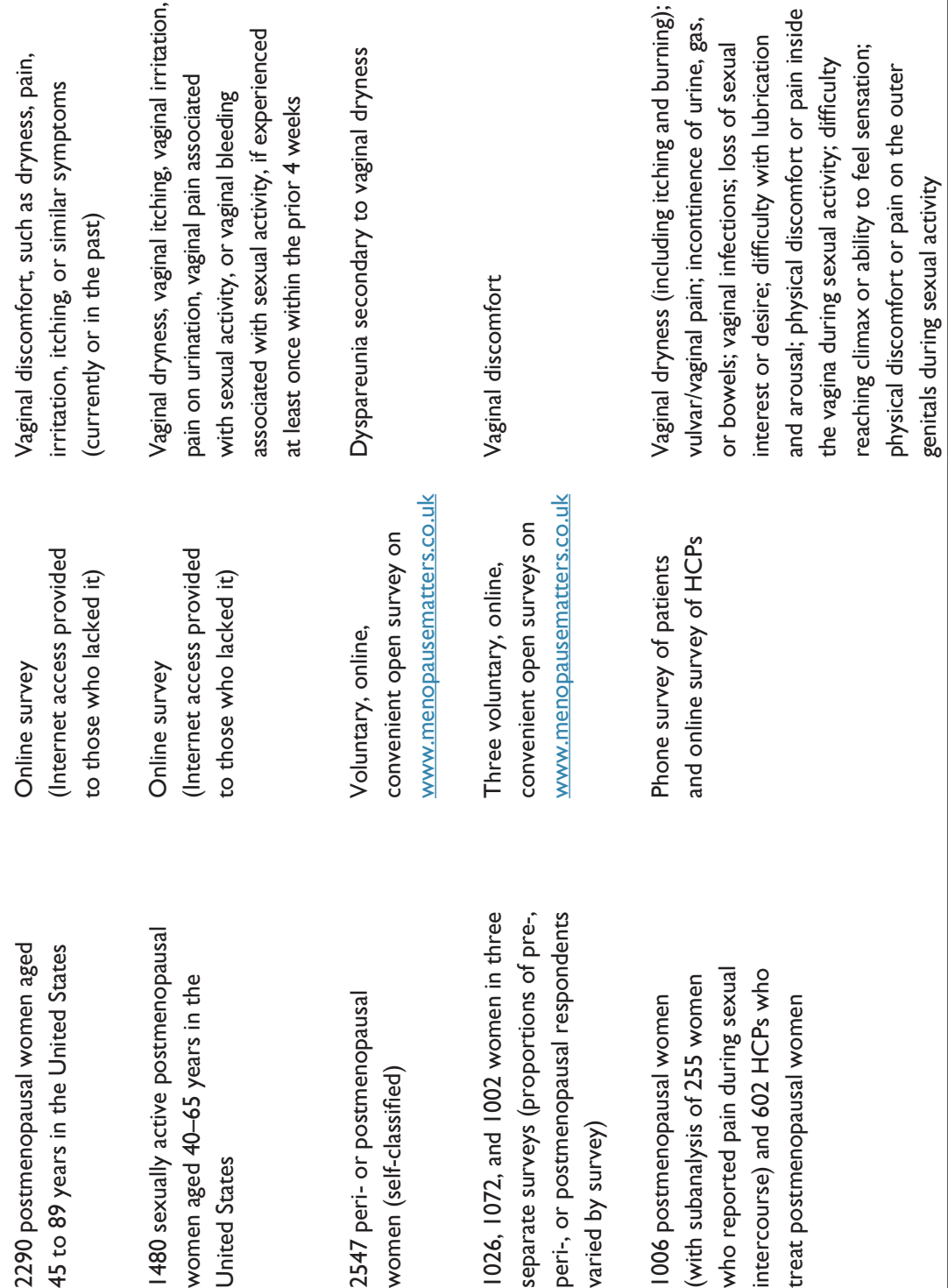

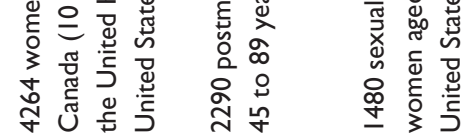

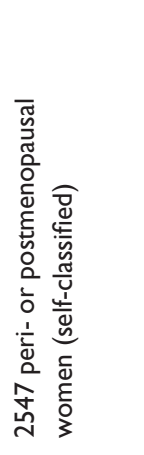

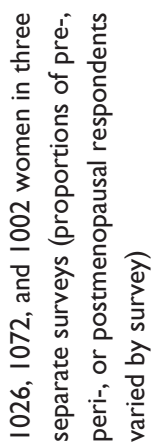

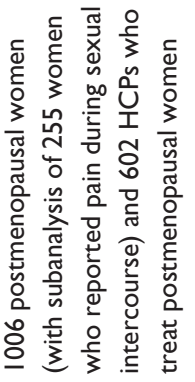

子唡高

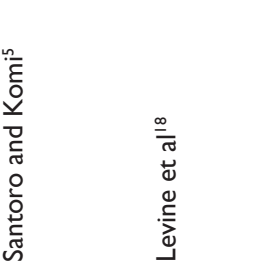

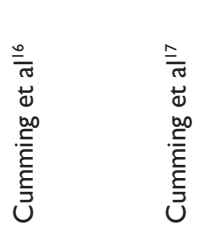

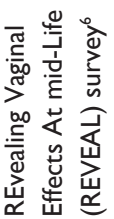

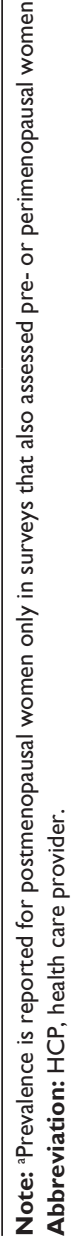




\section{Effect of vulvovaginal discomfort on QoL}

Vulvovaginal symptoms can also affect aspects of women's lives beyond physical health. In the Women's Voices in the Menopause study, about half (52\%) of the respondents reported at least some degree of negative impact, including negative consequences for their sex life (40\%), self-esteem (17\%), marriage/relationship (13\%), and social life (7\%), although $38 \%$ reported that their discomfort had not affected them much. ${ }^{7}$ Many women also reported that vaginal discomfort made them "feel old" (32\%) and gave them a lower QoL (14\%). In another study, postmenopausal women agreed that long-term VVA symptoms adversely affected their sexual interest (59\%), intimacy and relationship with a partner (55\%), $\operatorname{mood}(42 \%)$, and self-esteem $(34 \%) .{ }^{19}$ Additionally, a study by Cumming et $\mathrm{al}^{17}$ found that many women have tried to hide their vaginal dryness/discomfort from their partner ( $61 \%$ of peri- and postmenopausal women) and have made excuses to avoid intercourse because of their symptoms ( $42 \%$ of peri- and postmenopausal women). Respondents also reported that vaginal dryness/discomfort had affected their confidence ( $62 \%$ of peri- and postmenopausal women). ${ }^{17}$

\section{Association of VVA with sexual dysfunction}

Vulvovaginal symptoms may contribute to sexual problems and distress in postmenopausal women. Sexual desire has been found to decrease as women move through the menopausal transition, partially as a result of declining testosterone levels. ${ }^{20,21}$ Levine et al ${ }^{18}$ found that postmenopausal sexually active women with sexual dysfunction, as defined using the Arizona Sexual Experiences Scale questionnaire, were nearly four times more likely to have symptoms of VVA than those without sexual dysfunction. ${ }^{22}$ Also, the co-occurrence of sexual dysfunction and its separate domains and VVA in this analysis population was high; for women with VVA, $40 \%$ also reported overall sexual dysfunction, $24 \%$ lack of desire, $34 \%$ arousal difficulties, and $19 \%$ orgasm difficulties. ${ }^{22}$ These results are complemented by a separate large study of adult women (Prevalence of Female Sexual Problems Associated with Distress and Determinants of Treatment Seeking; PRESIDE), which found that the prevalence of distressing sexual problems, as measured by the Female Sexual Distress Scale, ${ }^{23}$ peaked at $14.8 \%$ in middle-aged women aged 45 to 64 years compared with women who were younger (aged 18-44 years, $10.8 \%$ ) or older (aged $\geq 65$ years, $8.9 \%$ ). ${ }^{24}$

In a second study by Cumming et al, ${ }^{16}$ more than onethird (38\%) of perimenopausal women and more than half $(56 \%)$ of postmenopausal women reported dyspareunia secondary to vaginal dryness. Most of these women $(78 \%$ and $87 \%$ in the perimenopausal and postmenopausal groups, respectively) considered dyspareunia to be a factor in their loss of libido. ${ }^{16}$ In another study, difficulty with lubrication was cited by $39 \%$ of women aged 57 to 85 years. ${ }^{25}$ The survey by Cumming et a ${ }^{16}$ also screened peri- and postmenopausal respondents for hypoactive sexual desire disorder (HSDD) using the Brief Profile of Female Sexual Function ${ }^{26}$ and found that respondents screening positive for HSDD overwhelmingly felt that vaginal dryness was a factor in their reduced libido (90\% of respondents). ${ }^{16}$ Likewise, a study of Italian women in surgical menopause found that vaginal dryness was significantly more reported by women with a decline of sexual desire than in those without a decline in desire $(63.2 \%$ versus $30.2 \% ; P=0.001) .{ }^{27}$ In the Study of Women's Health Across the Nation, women reporting vaginal dryness were more likely to report dyspareunia and lower arousal. ${ }^{20}$

Although many studies published over the last 30 years have shown that the frequency of sexual intercourse declines with age, ${ }^{28}$ a considerable proportion of postmenopausal women are sexually active. ${ }^{12,16}$ In examining the baseline characteristics of women participating in the hormone therapy trials of the Women's Health Initiative, Gass et $\mathrm{a}^{11}$ found that about $61 \%$ of women aged 50 to 59 years were sexually active, followed by $45 \%$ of women aged 60 to 69 years and $28 \%$ of women aged 70 to 79 years. Nearly two-thirds (63\%) of these women were satisfied with their sexual activity at the time of the survey, but of those dissatisfied, the majority (57\%) would prefer more sexual activity. Women with clinically evident VVA were more likely to report sexual inactivity. ${ }^{11}$

\section{Tolerating painful sex as a result of VVA}

Many postmenopausal women continue to have sex, even though it is painful. In the REvealing Vaginal Effects At midLife (REVEAL) study, one-quarter of women reported that they experienced dyspareunia at least sometimes. ${ }^{6}$ Of this dyspareunia subgroup, $72 \%$ engaged in sexual intercourse at least once a month and $34 \%$ at least once a week, despite the pain they were experiencing. Remarkably, $80 \%$ of the dyspareunia subgroup reported that they had learned to live with the vulvar and vaginal symptoms of menopause, such as dryness, as a normal part of getting older (compared with $51 \%$ of all respondents); $30 \%$ of women who experience dyspareunia said that the pain required interruption or discontinuance of sexual activity. ${ }^{6}$ Also in the REVEAL study, $56 \%$ of the dyspareunia subgroup said they were less sexually active as a result of the pain, while $6 \%$ said the pain prevented any attempt at sexual activity. ${ }^{6}$ The Study of Women's Health Across the Nation reported comparable frequency of intercourse between 
premenopausal women and early perimenopausal women who reported more pain with intercourse. ${ }^{29}$ Therefore, it appears that while some women tolerate painful sex, others may reduce their frequency of sexual activity or discontinue sexual activity entirely. In each case, a clinical need is evident.

\section{Urinary symptoms associated with VVA}

VVA may also be associated with lower urinary tract symptoms, such as dysuria, urgency, frequency, nocturia, incontinence, and recurrent UTIs. In any given year, about $8 \%$ of postmenopausal women may have an episode of UTI, and about 4\% may have two or more episodes. ${ }^{30}$ Evidence suggests that LET, but not systemic estrogen therapy, may prevent urinary infections and improve symptoms, ${ }^{31,32}$ including incontinence, frequency, nocturia, and urgency. ${ }^{33}$ Although this review focuses primarily on the vulvovaginal symptoms of VVA, urinary symptoms also have a high prevalence in older women and may have negative effects on QoL and sexual activity. ${ }^{34}$ The PRESIDE study, ${ }^{35}$ for example, found a correlation between distressing sexual problems in women and urinary incontinence. Treating vulvovaginal symptoms with LET may address urinary complaints as well. ${ }^{36}$

\section{Lack of understanding of vulvovaginal health}

Many postmenopausal women are uninformed about midlife vulvovaginal health and its importance. In one study, 87\% of postmenopausal women agreed with the statement, "My sexual health is important to me," 6 and in another, $84 \%$ of peri- and postmenopausal women answered "yes" to "Is an active sex life important?"16 So while most women value the importance of sex and sexual health, there is still a substantial minority that does not. In the REVEAL survey, only $9 \%$ of postmenopausal women disagreed with the statement, but this relatively small percentage potentially corresponds to 4.5 million women (based on an estimated 50 million postmenopausal women in the United States). ${ }^{6}$ These women likely have a variety of reasons for deprioritizing their sexual health, including the lack of a partner, other health concerns, or avoidance of sex because of vulvovaginal discomfort. However, women may benefit from receiving basic information about the potential advantages of achieving or maintaining sexual health in their peri- and postmenopausal years.

The VIVA study also investigated women's knowledge of vulvovaginal health issues. ${ }^{8}$ Many women (42\%) with vaginal discomfort realized that their condition was a symptom of menopause, although few (4\%) were able to attribute "dryness, itching, burning or soreness in the vagina, or pain during intercourse" to "vaginal atrophy." More than one-third (37\%) recognized vaginal discomfort as a chronic condition, but $45 \%$ did not know if it was chronic or acute; $18 \%$ thought it was an acute condition, despite the fact that $75 \%$ of women in the study had experienced symptoms for at least a year. ${ }^{8}$ In a separate study, ${ }^{19}$ postmenopausal women with vaginal discomfort were asked if they would be more likely to seek treatment if they knew it was a treatable medical condition called "vaginal atrophy" that could cause urogenital complications if left untreated. Nearly half of the women (44\%) reported that they would be "very likely" to seek treatment. ${ }^{19}$ These responses highlight the importance of discussing the root cause of VVA (estrogen deficiency) with postmenopausal women.

\section{Underdiagnosis and undertreatment of VVA}

Although many women experience vulvovaginal symptoms with menopause, they often do not seek medical help..$^{7,8,16}$ Approximately one-third (32\%) of the symptomatic respondents in the VIVA study, for example, had never seen an HCP for the treatment of vaginal discomfort and $28 \%$ waited for more than 1 year, ${ }^{8}$ suggesting that VVA is an underdiagnosed and undertreated condition among postmenopausal women. Because none of the key surveys asked if a physician had formally diagnosed symptomatic patients with VVA, the true rate of diagnosis in these populations is not known and cannot be directly compared with the proportion of women with symptoms and the proportion of women receiving treatment. There is, however, a clear discrepancy between the reported incidence of symptoms (see Table 1) and the reported incidence of treatment, suggesting a need for improved diagnosis and management of VVA.

In the VIVA study, more women with vaginal discomfort used over-the-counter lubricating products, including gels and creams (49\%), compared with prescription hormonal oral tablets and patches $(22 \%)$, vaginal hormone creams (13\%), vaginal hormone tablets (12\%), and vaginal hormone rings $(1 \%){ }^{8}$ Additionally, $22 \%$ of women with vaginal discomfort had not tried any of the treatments mentioned in the survey; these included those just mentioned as well as vaginal hormone suppositories and mineral/vitamin supplements (neither of which is approved in the United States for treating VVA). In Women's Voices in the Menopause, 63\% of women had never been prescribed any treatment for vaginal discomfort as a result of menopause, while 19\% had been prescribed treatment in the past and only $17 \%$ were currently undergoing treatment. ${ }^{7}$ The number of women treated with prescription (or hormone-based) therapy for vulvovaginal 
discomfort varied by country, ${ }^{7,8}$ with women in the United States, Canada, and the United Kingdom being treated less frequently than women in Finland and Sweden. ${ }^{7}$

In a UK-based survey, Cumming et $\mathrm{al}^{16}$ reported that only $28 \%$ of perimenopausal women and $46 \%$ of postmenopausal women who were experiencing dyspareunia secondary to vaginal dryness and who believed this to be a factor in their loss of libido discussed the issue with their HCP. Of those who had a discussion, only $36 \%$ of perimenopausal respondents and $55 \%$ of postmenopausal respondents were on treatment. Among women with HSDD based on their answers to the Brief Profile of Female Sexual Function, ${ }^{26}$ $40 \%$ had discussed dryness with an HCP and of those only $51 \%$ were on treatment. ${ }^{16}$ While the self-selecting nature of the sample may have introduced some bias, the results of this study exemplify how women who are candidates for therapy are missed at the diagnosis and treatment stages. ${ }^{16}$

Women who seek treatment for vulvovaginal discomfort are clearly bothered by their condition, and with treatment, many women report improvements in their everyday life, sex life, QoL, and their relationships. ${ }^{7}$ Women who have been diagnosed with VVA should be encouraged to begin managing their condition with appropriate treatment, following the guidelines of the North American Menopause Society, the International Menopause Society, and the Endocrine Society. ${ }^{12,37,38}$

\section{Lack of awareness of treatment options for VVA}

Many postmenopausal women are unaware of the recommended treatment options, which may include LET, for vulvovaginal discomfort. ${ }^{7,8}$ In Women's Voices in the Menopause, $42 \%$ of women did not realize that local treatment was available for vaginal discomfort related to menopause. ${ }^{7}$ Awareness was country-specific, with those in the United States having the greatest lack of awareness (51\%) and those in Finland having the least lack of awareness (10\%). VIVA reported that most women $(60 \%)$ were aware of over-the-counter options, such as lubricating gels and creams, although fewer were aware of prescription therapies. ${ }^{8}$ Among all categories of prescription therapies, women were most aware of hormonal oral tablets and patches (45\%), which may be recommended by some HCPs when there is an additional indication for systemic therapy, such as the relief of moderate to severe vasomotor symptoms due to menopause or the prevention of postmenopausal osteoporosis. ${ }^{39}$ Awareness of local hormone therapies, such as vaginal hormone creams (41\%), vaginal hormone tablets $(23 \%)$, and vaginal hormone rings $(12 \%)$, was lower than awareness of oral tablets and patches. ${ }^{39}$ In a separate study, $67 \%$ of women said that they did not have enough information to make an informed choice about whether or not to start hormone therapy (therapy was not separated into local or systemic). ${ }^{17}$ These results suggest that there is a need to increase awareness of recommended treatment options for vulvovaginal discomfort among postmenopausal women.

Although about two-thirds of women who are prescribed hormonal treatment are likely to report positive effects, ${ }^{7}$ many women are concerned about safety issues. ${ }^{8}$ The VIVA study investigated specific concerns about systemic and local hormone therapy separately. ${ }^{8}$ The primary concerns about systemic therapy, including both oral tablets and patches, were an increased risk of breast cancer (a concern reported by $53 \%$ of women) and an increased risk of developing a stroke or blood clot (a concern reported by $46 \%$ of women). ${ }^{8}$ These concerns were also expressed regarding LET, although to a lesser extent: $27 \%$ of women were concerned about an increased risk of breast cancer, whereas $24 \%$ were concerned about an increased risk of developing a stroke or blood clot. ${ }^{8}$ Strikingly, nearly half (46\%) of the women surveyed in VIVA did not know what perceptions (positive or negative) to associate with LET, illustrating a need for patient education. Women do not clearly understand the differences in the risks and benefits associated with local versus systemic therapy. ${ }^{12,39}$ Interestingly, $30 \%$ of women asserted that they would not consider LET, even if they knew it was effective and capable of maintaining normal hormone levels. ${ }^{8}$ However, $49 \%$ of women would be willing to try it and $20 \%$ were undecided, ${ }^{8}$ indicating that the majority of women, although they may be misinformed about LET, are receptive to additional information.

\section{Sources of information about vulvovaginal health}

When women in the VIVA study were asked what sources they had used or would use to understand vulvovaginal symptoms and/or treatment options, half cited their primary care doctor (50\% overall; $49 \%$ United States) or their gynecologist (46\% overall; 56\% United States). ${ }^{8}$ Approximately $30 \%$ of women cited medical websites, women's health websites, or menopause websites; $19 \%$ printed information in their doctor's office; $15 \%$ magazines; and 14\% friends. This information from non-HCP sources, such as the Internet and other women, may not be accurate or complete.

The PRESIDE study found that women who formally sought medical help for distressing sexual problems were generally younger than women who sought no help or who only sought help anonymously from printed material, television, radio, or Internet sources. ${ }^{35}$ Among women who formally 
sought medical help, younger women (aged $<65$ years) more often initiated a discussion with their HCP than older women (aged $\geq 65$ years), and older women spoke with a primary care physician (54\%) more often than with a gynecologist $(30 \%) .{ }^{35}$ Less than half of women $(44 \%)$ responding to the international VIVA study felt that there is enough information available about the symptoms and treatment of vulvovaginal discomfort. ${ }^{8}$ Finland was an outlier in this regard, with $76 \%$ of women reporting that enough information was available, compared with $37 \%$ to $42 \%$ in other countries. ${ }^{8}$

\section{Unwillingness of patients and HCPs to discuss sexual health}

Many postmenopausal women and their HCPs hesitate to discuss in an open conversation sexual health in general and vulvovaginal health, specifically; this presents a major challenge for diagnosing and managing VVA (see the section titled "Underdiagnosis and undertreatment of VVA").

\section{Patients' main concerns}

Only $38 \%$ of the women surveyed in REVEAL (a US-based study) had spoken to an HCP about their sexual health in the past year. ${ }^{6}$ Remarkably, some respondents $(41 \%)$ had not talked to anyone about their sexual health in the past year, even with their partners or friends. ${ }^{6}$ Consistent with the data from PRESIDE, this subset increased with age: $29 \%$ for women aged 45 to 49 years, $35 \%$ for women aged 50 to 54 years, $42 \%$ for women aged 55 to 59 years, and $49 \%$ for women aged 60 to 65 years. ${ }^{6}$ About half (47\%) of the respondents in REVEAL agreed that it is still taboo in society for postmenopausal women to acknowledge experiencing vulvovaginal symptoms. ${ }^{6}$

When asked why sexual or vulvovaginal health topics are not discussed, women typically provide a reason that falls into one of three major categories: (1) embarrassment; (2) the belief that nothing can be done; and (3) the belief that the topic is not appropriate to discuss with an HCP (Table 2). Other reasons include thinking that the HCP is too busy, ${ }^{6}$ thinking that the HCP might be embarrassed, ${ }^{6}$ or wishing someone else (such as an HCP) would initiate the conversation. ${ }^{7}$ The degree to which these reasons are cited varies by country, with women in the United States reporting more embarrassment than women in Canada, Sweden, Finland, or the United Kingdom. ${ }^{7}$

Additionally, in a study of both men and women aged 57 to 85 years, $38 \%$ of men had discussed sex with a physician since age 50 years, while only $22 \%$ of women had done so. ${ }^{25}$ This discrepancy may result at least partially from societal constraints, which were explored in the REVEAL study. ${ }^{6}$ Most respondents (ie, postmenopausal women aged 55-65 years) agreed that society constrains the sexual expression of women their age more than that of men their age $(75 \%)$, that society is more accepting of discussing men's physical sexual problems than women's (73\%), and that society would prefer to believe that women their age do not have sex $(53 \%$ of all respondents; $60 \%$ of respondents aged $60-65$ years).

Table 2 Self-reported reasons for not discussing vulvovaginal health or dyspareunia with HCP

\begin{tabular}{|c|c|c|c|}
\hline Reason & Language used in survey & Rate among respondents & Reference \\
\hline \multirow[t]{3}{*}{ Embarrassment } & $\begin{array}{l}\text { "It makes me uncomfortable/ } \\
\text { embarrassed." }\end{array}$ & $47 \%$ of those with vaginal discomfort & $\begin{array}{l}\text { Women's Voices } \\
\text { in the Menopause }\end{array}$ \\
\hline & "I am embarrassed." & $\begin{array}{l}39 \% \text { of those who have not talked } \\
\text { to an HCP about dyspareunia }\end{array}$ & REVEAL $^{6}$ \\
\hline & $\begin{array}{l}\text { Embarrassed about sexual } \\
\text { problems }^{23}\end{array}$ & $\begin{array}{l}59 \% \text { of women who did not seek help } \\
\text { were at least moderately embarrassed }\end{array}$ & PRESIDE ${ }^{35}$ \\
\hline \multirow[t]{2}{*}{$\begin{array}{l}\text { Belief that nothing } \\
\text { can be done }\end{array}$} & “It's just part of growing older." & $39 \%$ of those with vaginal discomfort & $\begin{array}{l}\text { Women's Voices } \\
\text { in the Menopause }\end{array}$ \\
\hline & $\begin{array}{l}\text { "There is nothing than can be } \\
\text { done medically to help me." }\end{array}$ & $\begin{array}{l}26 \% \text { of those who have not talked } \\
\text { to an HCP about dyspareunia }\end{array}$ & REVEAL $^{6}$ \\
\hline \multirow{3}{*}{$\begin{array}{l}\text { Belief that it is an } \\
\text { inappropriate topic } \\
\text { to discuss with an } \mathrm{HCP}\end{array}$} & $\begin{array}{l}\text { "I do not think other people want } \\
\text { to hear about my vaginal problems." }\end{array}$ & $59 \%$ of those with vaginal discomfort & $\begin{array}{l}\text { Women's Voices } \\
\text { in the Menopause }\end{array}$ \\
\hline & $\begin{array}{l}\text { "It is private and does not } \\
\text { concern others." }\end{array}$ & $4 I \%$ of those with vaginal discomfort & $\begin{array}{l}\text { Women's Voices } \\
\text { in the Menopause }\end{array}$ \\
\hline & $\begin{array}{l}\text { "It is not an appropriate discussion } \\
\text { to have with an HCP." }\end{array}$ & $\begin{array}{l}23 \% \text { of those who have not talked } \\
\text { to an HCP about dyspareunia }\end{array}$ & REVEAL $^{6}$ \\
\hline
\end{tabular}

Abbreviations: HCP, health care provider; REVEAL, Revealing Vaginal Effects at Midlife study; PRESIDE, Prevalence of Female Sexual Problems Associated with Distress and Determinants of Treatment Seeking study. 


\section{Patients waiting to report symptoms}

In the VIVA study, nearly half (47\%) of women who eventually saw an HCP about their symptoms waited more than 6 months, whereas $28 \%$ waited more than 1 year and $15 \%$ waited more than 2 years. ${ }^{8}$ Similarly, the Women's Voices in the Menopause study found that $25 \%$ of women $(32 \%$ of women in the United States) who had been prescribed treatment for their vulvovaginal symptoms had experienced symptoms for at least 1 year, while $5 \%$ to $11 \%$ of women (depending on country, $11 \%$ in the United States) had waited at least 3 years. $^{7}$ Some of these women may have simply been waiting for an HCP to initiate a conversation about vulvovaginal symptoms or sexual health. ${ }^{7}$ Others may believe that such changes would resolve or that they are a normal part of aging. ${ }^{38}$

\section{Patient preferences with terminology}

When discussing vulvovaginal symptoms and VVA with patients, HCPs should be mindful that women are generally not familiar or comfortable with the term "vaginal atrophy." In the VIVA study, about one-third (32\%) of women felt that the term "vaginal dryness" was appropriate to describe "dryness, itching, burning, or soreness in the vagina or pain during intercourse," whereas only $11 \%$ preferred the term "vaginal discomfort." Very few women considered the terms "poor vaginal health" (2\%), "vaginal dysfunction" $(2 \%)$, or "vaginal atrophy" $(2 \%)$ to be suitable. ${ }^{8}$ These preferences may be helpful to keep in mind when broaching the subject of vulvovaginal health.

\section{HCP perspective on discussing vulvovaginal health and role in improving diagnosis and treatment}

Few surveys investigate vulvovaginal health from the perspective of the HCP. In the HCP portion of the REVEAL study, the survey responses of $602 \mathrm{HCPs}$ (200 primary care physicians, 202 obstetrician/gynecologists, and 200 nurse practitioners) were compiled. ${ }^{6}$ Ninety-five percent of HCPs thought that treating a woman's vulvovaginal health was important to her overall physical health, and most reported that they discussed dyspareunia at least sometimes (36\% "often;" $49 \%$ "sometimes"). ${ }^{6}$ However, $44 \%$ of women who experienced dyspareunia and spoke to an HCP said that they initiated the conversation themselves; only $10 \%$ said that their HCP initiated the conversation. ${ }^{6}$ Multiple factors may influence the degree to which HCPs discuss sexual topics with patients, including lack of time, lack of training/experience, fear of embarrassing themselves or their patients, or even personal religious beliefs..$^{40}$

\section{Discussion and practice recommendations}

The surveys described in this review reveal a large population of menopausal women suffering in silence with VVA-related symptoms that are significantly impacting their QoL, including their sexual relationships and self-esteem. In addition, the surveys indicate that many of these women do not discuss their symptoms and that many lack information about the possibility of effective treatment. Further research is needed to examine the impact of VVA on partners of menopausal women and to explore outcomes, including sexual functioning/satisfaction and QoL, for women whose VVA has been treated. Future studies should also evaluate regional differences in women's expectations and experiences, such as those that are related to their treatment options and the health care system. The improved recognition, diagnosis, and treatment of VVA depend on increased communication between patients and HCPs regarding midlife vulvovaginal changes and effective, well tolerated treatment options for menopause-related vulvovaginal discomfort.

With improved health care, women are living longer in the postmenopausal hypoestrogenic state. HCPs should communicate with their patients about the potential manifestations and management of VVA so that symptomatic women may seek appropriate treatment rather than accepting pain and discomfort as a natural consequence of aging. Because many postmenopausal women, especially older women, may no longer see an obstetrician/gynecologist regularly, it is imperative to educate all clinicians, including those in internal medicine, family physicians, and other primary care providers, about the full impact of VVA and the need to proactively and empathically address this condition. For example, a diagnosis of VVA should be considered for postmenopausal women who present to their primary care physician with a history of recurrent UTIs or worsening symptoms of urinary urgency.

HCPs may improve the diagnosis and treatment of VVA by initiating conversations at routine examinations to increase patient awareness and understanding of midlife vulvovaginal changes and treatment options. Studies of the patient-HCP dialogue have indicated that, in the case of potentially sensitive issues of sexuality, patients may not offer complaints spontaneously, but will reveal them after being asked. ${ }^{41}$ Patients often prefer screening "ubiquity" statements that 
Table 3 Clinical findings indicating vulvovaginal atrophy

- Pale, smooth, shiny, or friable/unrugated epithelium

- Loss of elasticity of genital skin

- Vulvar dermatoses, lesions, or erythema

- Urethral caruncle or polyps

- Low serum estrogen levels

- Elevated vaginal $\mathrm{pH} \geq 5.5$

- Thinning of endometrial uterine lining

- Change in cytology of vaginal cells to primarily parabasal and intermediate cells

Note: Data from ${ }^{43-45}$.

address the concerns of their group..$^{21,42}$ An example of such a statement would be, "Many women find after menopause that they experience vaginal dryness, irritation, or pain during sex. Have you experienced anything like that?" The HCP's use of focused questions that model the level of explicitness desired from the patient can elicit more specific information. HCPs can then use open-ended questions to follow up positive responses. In addition HCPs may schedule a follow-up visit if additional time is required to address sexual issues. ${ }^{21}$ All HCPs who regularly see postmenopausal women have a responsibility to their patients to routinely ask about symptoms of VVA and to perform periodic clinical examinations to detect VVA (Table 3 ). ${ }^{43-45}$ In addition, providing peri- and postmenopausal patients with at least one or two information leads, such as pamphlets or reliable websites, may motivate women to become better-informed advocates of their own vulvovaginal health and to then seek treatment, if necessary.

\section{Acknowledgments}

Editorial assistance was provided by Pamela Barendt, $\mathrm{PhD}$, of ETHOS Health Communications, Newtown, Pennsylvania, with financial assistance from Novo Nordisk Inc, Princeton, New Jersey, in compliance with international guidelines on Good Publication Practice. The authors received no remuneration of any kind for the development of this manuscript.

\section{Disclosure}

During the past 2 years, Dr Nappi had a financial relationship (lecturer, member of advisory boards and/or consultant) with Bayer-Schering Pharma, Eli Lilly, Merck Sharpe and Dohme, Novo Nordisk, Pfizer Inc, and Teva/Theramex. Dr Kellogg-Spadt has had financial relationships (lecturer, consultant) with Warner Chilcott, Novo Nordisk, and Neocutis. Dr Parish has had financial relationships (member of advisory boards) with Novo Nordisk, Emotional Brain,
Shionogi, and Sprout Pharmaceuticals. Dr Krychman has had a financial relationship (lecturer and consultant) with Warner Chilcott, Novo Nordisk, Shionogi, Sprout, Palatin, and Pfizer. Dr Kingsberg has financial relationships with Novo Nordisk, Trimel, BioSante, Emotional Brain, Pfizer, Shionogi, Sprout, Viveve, and Palatin. Dr James A Simon has served or is currently serving as a consultant to or on the advisory boards of Abbott Laboratories (Abbott Park, IL, USA), Agile Therapeutics Inc (Princeton, NJ, USA), Amgen Inc (Thousand Oaks, CA, USA), Ascend Therapeutics (Herndon, VA, USA), Azur Pharma Inc (Fitzwilliam Square, Dublin), BioSante (Lincolnshire, IL, USA), Boehringer Ingelheim (Ingelheim, Germany), Depomed Inc (Menlo Park, CA, USA), Fabre-Kramer (Houston, TX, USA), Intimina by Lelo, Inc (San Jose, CA, USA), Laboratoire HRA Pharma (Paris, France), Meditrina Pharmaceuticals (Ann Arbor, MI, USA), MD Therapeutics (Boca Raton, FL, USA), Merck (Whitehouse Station, NJ, USA), Merrion Pharmaceuticals (Wilmington, NC, USA), NDA Partners LLC (Lakewood Ranch, FL, USA), Novo Nordisk (Bagsvaerd, Denmark), Novogyne (East Hanover, NJ, USA), Pfizer Inc (New York, NY, USA), Shionogi Inc (Florham Park, NJ, USA), Slate Pharmaceuticals Inc (Durham, NC, USA), Sprout Pharmaceuticals (Raleigh, NC, USA), Teva Pharmaceutical Industries Ltd (Jerusalem, Israel), Trovis Pharmaceuticals LLC (Newton, MA, USA), Warner Chilcott (Rockaway, NJ, USA), and Watson Pharmaceuticals Inc (Corona, CA, USA). He has received or is currently receiving grant/research support from BioSante (Lincolnshire, IL, USA), Boehringer Ingelheim (Ingelheim, Germany), EndoCeutics Inc (Quebec City, Quebec, Canada), Novo Nordisk (Bagsvaerd, Denmark), Novogyne (East Hanover, NJ, USA), Palatin Technologies (Cranbury, NJ, USA), Teva Pharmaceutical Industries Ltd (Jerusalem, Israel), and Warner Chilcott (Rockaway, NJ, USA). He has also served or is currently serving on the speakers bureaus of Amgen Inc (Thousand Oaks, CA, USA), Ascend Therapeutics (Herndon, VA, USA), Bayer (Leverkusen, Germany), Boehringer Ingelheim (Ingelheim, Germany), Merck (Whitehouse Station, NJ, USA), Novartis (Basel, Switzerland), Novo Nordisk (Bagsvaerd, Denmark), Novogyne (East Hanover, NJ, USA), Teva Pharmaceutical Industries Ltd (Jerusalem, Israel), and Warner Chilcott (Rockaway, NJ, USA). He is currently the part-time Chief Medical Officer for Sprout Pharmaceuticals (Raleigh, NC, USA). The authors report no other conflicts of interest in this work. 


\section{References}

1. US Census Bureau. Statistical Abstract of the United States: 2012. Table 104. Expectation of Life at Birth, 1970 to 2008, and Projections, 2010 to 2020. Washington, DC: US Census Bureau; 2011. Available from: http://www.census.gov/compendia/statab/2012/tables/12s0105. pdf. Accessed April 6, 2012.

2. US Census Bureau. Statistical Abstract of the United States: 2012. Table 7. Resident Population by Sex and Age: 1980 to 2010. Washington, DC: US Census Bureau; 2011. Available from: http:// www.census.gov/compendia/statab/2012/tables/12s0007.pdf. Accessed April 6, 2012.

3. Nichols HB, Trentham-Dietz A, Hampton JM, et al. From menarche to menopause: trends among US women born from 1912 to 1969. Am J Epidemiol. 2006;164(10):1003-1011.

4. Obermeyer CM, Reher D, Alcala LC, Price K. The menopause in Spain: results of the DAMES (Decisions At MEnopause) study. Maturitas. 2005;52(3-4):190-198.

5. Santoro N, Komi J. Prevalence and impact of vaginal symptoms among postmenopausal women. J Sex Med. 2009;6(8):2133-2142.

6. Wyeth. REVEAL: Revealing Vaginal Effects at Mid-Life: Surveys of Postmenopausal Women and Health Care Professionals who Treat Postmenopausal Women. Madison, NJ: Wyeth; 2009. Available from: http://www.revealsurvey.com/pdf/reveal-survey-results.pdf. Accessed April 6, 2012.

7. Nappi RE, Kokot-Kierepa M. Women's voices in the menopause: results from an international survey on vaginal atrophy. Maturitas. 2010;67(3):233-238.

8. Nappi RE, Kokot-Kierepa M. Vaginal Health: Insights, Views and Attitudes (VIVA) - results from an international survey. Climacteric. 2012;15(1):36-44.

9. Mac Bride MB, Rhodes DJ, Shuster LT. Vulvovaginal atrophy. Mayo Clin Proc. 2010;85(1):87-94.

10. Bachmann GA, Nevadunsky NS. Diagnosis and treatment of atrophic vaginitis. Am Fam Physician. 2000;61(10):3090-3096.

11. Gass ML, Cochrane BB, Larson JC, et al. Patterns and predictors of sexual activity among women in the Hormone Therapy trials of the Women's Health Initiative. Menopause. 2011;18(11):1160-1171.

12. North American Menopause Society. The role of local vaginal estrogen for treatment of vaginal atrophy in postmenopausal women: 2007 position statement of The North American Menopause Society. Menopause. 2007;14(3 Pt 1):357-369; quiz 370-371.

13. Bygdeman M, Swahn ML. Replens versus dienoestrol cream in the symptomatic treatment of vaginal atrophy in postmenopausal women. Maturitas. 1996;23(3):259-263.

14. van der Laak JA, de Bie LM, de Leeuw H, de Wilde PC, Hanselaar AG. The effect of Replens on vaginal cytology in the treatment of postmenopausal atrophy: cytomorphology versus computerised cytometry. J Clin Pathol. 2002;55(6):446-451.

15. Panay N, Maamari R. Treatment of postmenopausal vaginal atrophy with 10- $\mu$ g estradiol vaginal tablets. Menopause Int. 2012;18(1):15-19.

16. Cumming GP, Currie HD, Moncur R, Lee AJ. Web-based survey on the effect of menopause on women's libido in a computer-literate population. Menopause Int. 2009;15(1):8-12.

17. Cumming GP, Herald J, Moncur R, Currie H, Lee AJ. Women's attitudes to hormone replacement therapy, alternative therapy and sexual health: a web-based survey. Menopause Int. 2007;13(2):79-83.

18. Levine KB, Williams RE, Hartmann KE. Vulvovaginal atrophy is strongly associated with female sexual dysfunction among sexually active postmenopausal women. Menopause. 2008;15(4 Pt 1):661-666.

19. Simon JA, Komi J. Vulvovaginal atrophy (VVA) negatively impacts sexual function, psychosocial well-being, and partner relationships. Proceedings of the North American Menopause Society (NAMS); October 3-6, 2007; Dallas, TX, USA.

20. Avis NE, Brockwell S, Randolph JF Jr, et al. Longitudinal changes in sexual functioning as women transition through menopause: results from the Study of Women's Health Across the Nation. Menopause. 2009;16(3):442-452.
21. Kingsberg S, Althof SE. Evaluation and treatment of female sexual disorders. Int Urogynecol J Pelvic Floor Dysfunct. 2009;20 Suppl 1: S33-S43.

22. McGahuey CA, Gelenberg AJ, Laukes CA, et al. The Arizona Sexual Experience Scale (ASEX): reliability and validity. J Sex Marital Ther. 2000;26(1):25-40.

23. Derogatis LR, Rosen R, Leiblum S, Burnett A, Heiman J. The Female Sexual Distress Scale (FSDS): initial validation of a standardized scale for assessment of sexually related personal distress in women. $J \mathrm{Sex}$ Marital Ther. 2002;28(4):317-330.

24. Shifren JL, Monz BU, Russo PA, Segreti A, Johannes CB. Sexual problems and distress in United States women: prevalence and correlates. Obstet Gynecol. 2008;112(5):970-978.

25. Lindau ST, Schumm LP, Laumann EO, Levinson W, O’Muircheartaigh CA, Waite LJ. A study of sexuality and health among older adults in the United States. N Engl J Med. 2007;357(8):762-774.

26. Rust J, Derogatis L, Rodenberg C, Koochaki P, Schmitt S, Golombok S. Development and validation of a new screening tool for hypoactive sexual desire disorder: The Brief Profile of Female Sexual Function (B-PFSF). Gynecol Endocrinol. 2007;23(11):638-644.

27. Nappi RE, Lello S, Melis GB, Albani F, Polatti F, Genazzani AR. LEI (Lack of tEstosterone Impact) survey in a clinical sample with surgical menopause. Climacteric. 2009;12(6):533-540.

28. Schneidewind-Skibbe A, Hayes RD, Koochaki PE, Meyer J, Dennerstein L. The frequency of sexual intercourse reported by women: a review of community-based studies and factors limiting their conclusions. J Sex Med. 2008;5(2):301-335.

29. Avis NE, Zhao X, Johannes CB, Ory M, Brockwell S, Greendale GA. Correlates of sexual function among multi-ethnic middle-aged women: results from the Study of Women's Health Across the Nation (SWAN). Menopause. 2005;12(4):385-398.

30. Brown JS, Vittinghoff E, Kanaya AM, Agarwal SK, Hulley S, Foxman B; for Heart and Estrogen/Progestin Replacement Study Research Group. Urinary tract infections in postmenopausal women: effect of hormone therapy and risk factors. Obstet Gynecol. 2001;98(6):1045-1052.

31. Eriksen B. A randomized, open, parallel-group study on the preventive effect of an estradiol-releasing vaginal ring (Estring) on recurrent urinary tract infections in postmenopausal women. Am J Obstet Gynecol. 1999;180(5):1072-1079.

32. Perrotta C, Aznar M, Mejia R, Albert X, Ng CW. Oestrogens for preventing recurrent urinary tract infection in postmenopausal women. Cochrane Database Syst Rev. 2008;(2):CD005131.

33. Cody JD, Richardson K, Moehrer B, Hextall A, Glazener CM. Oestrogen therapy for urinary incontinence in post-menopausal women. Cochrane Database Syst Rev. 2009;(4):CD001405.

34. Wennberg AL, Molander U, Fall M, Edlund C, Peeker R, Milsom I. A longitudinal population-based survey of urinary incontinence, overactive bladder, and other lower urinary tract symptoms in women. Eur Urol. 2009;55(4):783-791.

35. Shifren JL, Johannes CB, Monz BU, Russo PA, Bennett L, Rosen R. Help-seeking behavior of women with self-reported distressing sexual problems. J Womens Health (Larchmt). 2009;18(4):461-468.

36. Nappi RE, Davis SR. The use of hormone therapy for the maintenance of urogynecological and sexual health post WHI. Climacteric. 2012;15(3): 267-274.

37. Santen RJ, Allred DC, Ardoin SP, et al; for Endocrine Society. Postmenopausal hormone therapy: an Endocrine Society scientific statement. J Clin Endocrinol Metab. 2010;95(7 Suppl 1):s1-s66.

38. Sturdee DW, Panay N; for International Menopause Society Writing Group. Recommendations for the management of postmenopausal vaginal atrophy. Climacteric. 2010;13(6):509-522.

39. North American Menopause Society. The 2012 hormone therapy position statement of: The North American Menopause Society. Menopause. 2012;19(3):257-271.

40. Sobecki JN, Curlin FA, Rasinski KA, Lindau ST. What we don't talk about when we don't talk about sex: results of a national survey of US obstetrician/gynecologists. J Sex Med. 2012;9(5):1285-1294. 
41. Bachmann GA, Leiblum SR, Grill J. Brief sexual inquiry in gynecologic practice. Obstet Gynecol. 1989;73(3 Pt 1):425-427.

42. Sadovsky R, Alam W, Enecilla M, Cosiquien R, Tipu O, EtheridgeOtey J. Sexual problems among a specific population of minority women aged $40-80$ years attending a primary care practice. $J$ Sex Med. 2006;3(5):795-803.

43. Pandit L, Ouslander JG. Postmenopausal vaginal atrophy and atrophic vaginitis. Am J Med Sci. 1997;314(4):228-231.
44. Beard MK. Atrophic vaginitis. Can it be prevented as well as treated? Postgrad Med. 1992;91(6):257-260.

45. Osmers R, Völksen M, Schauer A. Vaginosonography for early detection of endometrial carcinoma? Lancet. 1990;335(8705):1569-1571.

International Journal of Women's Health

\section{Publish your work in this journal}

The International Journal of Women's Health is an international, peerreviewed open-access journal publishing original research, reports, editorials, reviews and commentaries on all aspects of women's healthcare including gynecology, obstetrics, and breast cancer. The manuscript management system is completely online and includes a very quick and fair peer-review system, which is all easy to use. Visit http://www.dovepress.com/testimonials.php to read real quotes from published authors.

\footnotetext{
Submit your manuscript here: http://www.dovepress.com/international-journal-of-womens-health-journal
} 